\title{
AS CONTRIBUIÇÕES DE VYGOTSKY AOS ESTUDOS SOBRE A LINGUAGEM DAS CRIANÇAS
}

\author{
VYGOTSKY'S CONTRIBUTIONS TO STUDIES \\ ABOUT CHILDREN'S LANGUAGE
}

\author{
Roberto Remígio Florêncio \\ Universidade Federal da Bahia - UFBA / IF Sertão - PE ${ }^{1}$ \\ Michele de Cassia Sabino Moreira \\ UNIVASF - Universidade Federal do vale do São Francisco ${ }^{2}$
}

\begin{abstract}
RESUMO
O presente artigo de revisão bibliográfica teve como objetivo investigar as contribuições da teoria sóciohistórica para o desenvolvimento da linguagem na criança. Fez-se uma abordagem qualitativa por meio de pesquisa bibliográfica buscando traçar os tópicos que pudessem responder a indagação da pesquisa: Qual a influência dos ambientes no desenvolvimento da linguagem infantil visto sobre a perspectiva sócio-histórica de Vygotsky? Por isso, o trabalho de pesquisa procurou se basear nas teorias e em estudos desenvolvidos a partir do autor. Com isso, foi possível identificar que o desenvolvimento da linguagem na criança sofre influências do ambiente em que está inserida. Vygotsky (1993) afirma que, mediada pela interação com outros indivíduos em determinado ambiente geo-histórico e sociocultural, a criança se torna capaz de desenvolver-se em sua capacidade linguística, em qualidade e quantidade, impulsionando posteriormente os avanços em seu desenvolvimento de pensamento, consequentemente em sua percepção, atenção e memória.
\end{abstract}

Palavras-chave: Desenvolvimento linguagem; Teoria Sócio-histórica; Ambiente social

\begin{abstract}
The present article of bibliographical revision had as objective to investigate the contributions of the sociohistorical theory to the development of language in a child. A qualitative approach was carried out by bibliographical research, seeking to outline the topics that could answer the research question: What is the influence of the environment in the development of children's language seen on Vygotsky's socio-historical perspective? Therefore, the research work sought to be based on Vygotsky's theories and studies developed by the author. With this study it was possible to identify that the development of language in children is influenced by the environment in which they are inserted. Vygotsky states that, mediated by interaction with other individuals in a certain historical-sociological-cultural environment, the child becomes capable to develop in his / her linguistic capacity in quality and quantity, later boosting the advances in his / her development of thinking, consequently in his/her perception, attention and memory.
\end{abstract}

Keywords: Language development; Socio-historical Theory; Social environment

\section{INTRODUÇÃO}

O estudo do desenvolvimento da linguagem na primeira infância, aliada às influências que o ambiente social exerce sobre ela, é de fundamental importância para profissionais da educação que estão junto a essas crianças, e para aqueles que tenham interesse em mergulhar neste mundo

\footnotetext{
${ }^{1}$ Doutorando em Educação - PPGE/UFBA; Mestre em Educação e Cultura (UNEB); Licenciado em Letras (UPE) e em Pedagogia (UNEB).

${ }^{2}$ Graduada em Pedagogia (Universidade Federal de Viçosa - UFV); Especialista em Desenvolvimento Infantil (UNIVASF); Mestranda em Educação (UNEB).
} 
de descobertas e aprendizado da infância, sejam pais ou outros profissionais que se identifiquem com essa temática. O interesse em se discutir os processos iniciais no desenvolvimento da linguagem na criança, sob a perspectiva sócio-histórica do psicólogo russo Lev Vygotsky ${ }^{3}$ (1993), deve se dar principalmente pelo fato de que o teórico discute a interação social do sujeito, como produtora do processo de desenvolvimento e crescimento deste, o que se identifica plenamente com o papel do educador na contemporaneidade, imbrincado pela relação família-escolacomunidade. Segundo o autor, esse desenvolvimento acontece de forma mediada pela relação que o indivíduo estabelece com os meios sociais e culturais. No caso do desenvolvimento linguístico, o autor nos ajuda a compreender que esta relação com o outro, que vai propiciar o desenvolvimento da linguagem, estabelece nítida dependência das interações entre o ambiente e a criança.

Para esse debate, colocou-se como indagação na pesquisa o seguinte questionamento: Sob a perspectiva sócio-histórica de Vygotsky, como se dá a influência dos ambientes no desenvolvimento da linguagem nos primeiros anos da criança? Por acreditar que a questão possa nos ajudar a entender como é construído esse desenvolvimento da fala na criança, surgem mais duas questões: Quais etapas ela vivencia para esse alcance? Quais seriam os elementos que potencializam esse desenvolvimento?

Daí, pensou-se como objetivo geral, a possibilidade de investigar as contribuições da teoria sócio-histórica de Vygotsky para o desenvolvimento da linguagem nos primeiros anos da criança. E, como objetivos específicos, tornou-se importante descrever sua importância nesta teoria, identificar quais as influências que os contextos sociais que as crianças estão inseridas desempenham no desenvolvimento da sua linguagem e, ainda, entender como esse desenvolvimento da linguagem se inter-relaciona com outros desenvolvimentos na primeira infância.

O contato com a teoria vygotskiana por meio dos livros, bases desta discussão, principalmente o livro " A construção do Pensamento e da Linguagem", possibilitou entender o processo de desenvolvimento da linguagem na criança como um processo que se desenvolve mediada por sistemas simbólicos representantes da realidade, sob influência dos ambientes. Sendo, assim é por meio dos signos, da palavra, dos instrumentos, que ocorre o contato com a cultura. O surgimento

\footnotetext{
${ }^{3}$ Lev Semyonovich Vygosty, psicólogo nascido na Rússia (União Soviética, na época) em 1896, é um dos mais importantes teóricos mundiais sobre o processo de aprendizagem, aquisição da linguagem e diversas teorias ligada à educação. Vygotsky, cujo sobrenome foi transliterado também como Vigotski e Vigotsky, teve sua obra reconhecida apenas após sua morte prematura em 1934, vitimado pela tuberculose. Fundador da escola soviética de psicologia histórico-cultural e considerado em todo o mundo o pai da pedagogia moderna, teve sua principal obra (Pensamento $e$ Linguagem) lançada apenas na década de 1950.

${ }^{4}$ A edição que apresenta a tradução do texto Integral do russo para o português, publicada pela Editora Martins Fontes, São Paulo: 2001.
} 
da linguagem, caracterizada pelo momento em que a criança começa a nomear os objetos, e estabelecer relações e associações, depende inicialmente da qualidade das interações estabelecidas com os adultos que a cercam. Desta forma, a linguagem é o principal mediador na formação e no desenvolvimento das funções psicológicas superiores.

Ela (a linguagem) constitui um sistema simbólico, elaborado no curso da história social do homem, que organiza os signos em estruturas complexas permitindo, por exemplo, nomear objetos, destacar suas qualidades e estabelecer relações entre os próprios objetos (LUCCI, 2006, p. 09).

Assim, nos estudos vygotskianos, o autor nos atualiza que a linguagem materializa e constitui as significações construídas no processo social e histórico. Quando os indivíduos a interiorizam, passam a ter acesso a estas significações que, por sua vez, servirão de base para que possam significar suas experiências, e serão estas significações resultantes que constituirão suas consciências, mediando, desse modo, suas formas de sentir, pensar e agir.

\section{METODOLOGIA}

Para obtenção das informações, o método utilizado foi baseado na abordagem qualitativa por meio da pesquisa de revisão bibliográfica sobre as temáticas que envolvem a linguagem e o seu processo de aquisição/construção desta, tomando-se como base a teoria sócio-histórica de Vygosty (1993: 2001). Como fonte de informações buscou-se artigos científicos por meio de pesquisa na base de dados da Scientific Eletronic Library Online (Scielo Brasil), selecionados por autores que tratem da temática, além de outras fontes de páginas de web sites e livros. Após a leitura dos mesmos, se construíra o texto a fim de responder a indagação proposta. Para organização e seleção do material e análise do conteúdo, seguimos as orientações de Gil (2008, p. 152), que propõem que seja desenvolvida em três etapas: 1. pré-análise: "inicia-se geralmente com os primeiros contatos com os documentos (leitura flutuante)". 2. exploração do material: fase caracterizada como mais longa, e "tem como objetivo administrar sistematicamente as decisões tomadas na pré-análise". 3. tratamento dos dados, inferência e interpretação: "objetivam tornar os dados válidos e significativos".

Por fim, cumpridas as etapas citadas, fizemos a análise do conteúdo selecionado, ordenando em tópicos a discussão com objetivo de tornar claro o que a teoria nos traz em resposta a indagação inicial da pesquisa. Tendo como intenção traçar os seguintes tópicos: Importância da Linguagem na Teoria sócio-histórica de Vygotsky; Contextos que se inter-relacionam no Desenvolvimento da na linguagem da criança; Desenvolvimento da linguagem e outros desenvolvimentos na primeira infância. 


\section{A LINGUAGEM, PELA TEORIA SÓCIO-HISTÓRICA DE VYGOTSKY}

Para Vygotsky (1993), a linguagem tem como principal função estabelecer o contato social, tanto nas crianças quanto nos adultos. Mediante isso, o autor declara que

a criança nasce apenas com as funções cognitivas elementares que se ampliam para as funções complexas a partir do contato com a cultura, o que não acontece automaticamente, mas sim por meio de intermediações de outros sujeitos, sendo essas intermediações responsáveis por formar significados e valores sociais e históricos (VYGOTSKY, 1991, apud FERRARI, 2014, p. 27).

Desta forma, a criança tem seu desenvolvimento da fala, desde o momento em que nasce, desenvolvida através do contato social, manifestada por meio do comportamento emocional, começando pelos choros, tão logo, vem os gritos e balbucios, até as primeiras palavras caracterizando assim essa etapa como estágios pré-intelectuais (VYGOTSKY, 2001). Essa forma de contato social desde os primeiros meses de vida é o que auxilia no desenvolvimento da fala posterior. Segundo Vygotsky (2001, p. 310),

a descoberta mais importante sobre o desenvolvimento do pensamento e da fala na criança e a de que, num certo momento, mais ou menos aos dois anos de idade, as curvas da evolução do pensamento e da fala, até então separadas, cruzam-se e coincidem para iniciar uma nova forma de comportamento muito característica do homem.

Ocorrendo assim, momentos de mudança na criança da qual a fala se torna intelectual, e o pensamento individualizado, caracterizado por dois momentos em que a criança que sofreu essa mudança começa a ampliar ativamente o seu vocabulário, tendo agora atitude de perguntar sobre como cada coisa nova chama e, consequentemente, seu repertório se amplia rapidamente (VYGOTSKY, 2001). Uma nova transformação acontece no desenvolvimento da fala da criança, antes dessa etapa das perguntas, quando a criança também assimila determinadas palavras, que para ela são estímulos condicionados ou substitutos de alguns objetos, pessoas, ações estados e desejos, neste período o conhecimento das palavras é o que aprende apenas com outras pessoas e por necessidades urgentes.

Outro grande salto acontece a partir do momento em que a criança passa a ver o novo objeto, e desenvolve a pergunta como isso se chama? Agora, a própria criança tem necessidade da palavra e, de forma ativa, busca assimilar o signo pertencente ao objeto, signo este que lhe serve para nomear e comunicar. Esta etapa foi caracterizada como o primeiro estágio do desenvolvimento da fala infantil (VYGOTSKY, 2001). Aparece aí um sentido psicológico, afetivo-volitivo, segundo os estudos sociointeracionistas, sendo a partir desse momento que a fala entra na fase intelectual do seu desenvolvimento: é como se a criança descobrisse a função simbólica da linguagem (VYGOTSKY, 2001). 
Um novo processo surge no desenvolvimento da fala infantil, um processo de linguagem interior para o desenvolvimento do pensamento, e o autor traz essa discussão como linguagem egocêntrica, que seria o diálogo interno da criança, ou seja, é a função expressiva e de descarga interna de pensamento, que vai assumir a função de operação, de planejamento, de solução de tarefas que surgem no comportamento. Assim podemos entender nas próprias palavras de Vygotsky:

a linguagem se toma psicologicamente interior antes de tornar-se fisiologicamente interior. A linguagem egocêntrica e uma linguagem interior por sua função, e uma linguagem para si, que se encontra no caminho de sua interiorização, uma linguagem já metade ininteligível aos circundantes, uma linguagem que já se enraizou fundo no comportamento da criança e ao mesmo tempo ainda e fisiologicamente externa, e não revela a mínima tendência a transformar-se em sussurro ou em qualquer outra linguagem semi-surda (2001, p. 64).

Em outras palavras, Vygotsky diz que a fala egocêntrica pode ser entendida através da "função primordial da fala, que é o contato social e a comunicação" (1998, apud MIRANDA, 2012, p. 04), e essa função permite a ocorrência do processo de transferência "dos modos sociais e cooperativos e de conduta" (VYGOTSKY, 1998, apud MIRANDA, 2012, p. 04) para a esfera de ordem das funções psíquicas superiores e pessoais.

Passado esse processo no desenvolvimento da fala da criança, em que se caracterizam por signos exteriores e operações externas, que são usadas como auxiliares na solução de problemas internos, passamos para o próximo estágio de desenvolvimento denominado de crescimento para dentro, nesta etapa:

as operações externas se interiorizam e passam por uma profunda mudança. A criança começa a contar mentalmente, a usar a "memória lógica", isto é, a operar com relações interiores em forma de signos interiores. No campo da fala, a isto corresponde a linguagem interior ou silenciosa. O que mais chama a atenção neste sentido e o fato de existir uma interação constante entre as operações externas e internas, uma se transformando na outra sem esforços e com frequência, e vice-versa (VYGOTSKY, 2001, p.138).

Assim, em síntese e para melhor compreensão, podemos resumir os estágios de desenvolvimento da fala infantil em quatro, segundo Vygotsky (1993):

1) estágio natural ou primitivo: que se refere à fala pré-intelectual e ao pensamento pré-verbal; 2) estágio da psicologia ingênua: aqui ocorre "a experiência que a criança tem das propriedades físicas do seu próprio corpo e dos objetos que a cercam e aplicação desta experiência ao uso dos instrumentos", considerada o primeiro "exercício da inteligência prática infantil" (VYGOTSKY, 1993, p. 50), além de ter o desenvolvimento linguístico bem desenvolvido. Nesta etapa também, acontece a utilização correta das formas e estruturas gramaticais, e, além disso, a criança pode falar com proposições subordinadas, como exemplo: como, porque, se, quando, mas; mesmo antes de obter 
o domínio das relações causais, condicionais ou temporais. Ocorre um domínio da linguagem antes de dominar a sintaxe do pensamento (VYGOTSKY, 1993).

3) estágio da fala egocêntrica: nesta fase, a criança utiliza "sinais externos por operações externas que são utilizadas como auxiliares para a solução dos problemas internos" (VYGOTSKY, 1993, p.50). E, no desenvolvimento da fala, ela recorre ao discurso egocêntrico (VYGOTSKY, 1993).

4) estágio do crescimento interior: neste estágio, "as operações externas interiorizam-se e sofrem uma profunda transformação durante esse processo" (VYGOTSKY, 1993, p.50). No desenvolvimento da fala, é o último estágio do discurso interior, silencioso, ou seja, o discurso interior se iguala ao discurso externo, que será transmitido através da fala (VYGOTSKY, 1993).

(...) os estudos desses estágios permitiram concluir que na medida em que as crianças se desenvolvem, dirigindo sua fala para comunicações específicas com os outros como, por exemplo, pedir comida ou brinquedo, elas começam a dirigir a fala para si mesmas, levando à internalização de palavras e à constituição da fala interior. Esta, por sua vez, envolve pensamentos verbais norteadores do comportamento e da cognição, processo fundamental no desenvolvimento e funcionamento psicológico humano, logo, na construção do conhecimento (VYGOTSKY, 1998 apud MIRANDA, 2012, p. 04).

No curso desse desenvolvimento, é possível entender que existe uma série de fatores que podem influenciar a formação do desenvolvimento da linguagem na criança, seus aspectos interiores e aqueles desenvolvidos pela relação exterior. Desta maneira, a relação exterior, materializada pelas instituições de educação infantil, como creches e pré-escolas no Brasil, é direcionada pela Base Nacional Comum Curricular (BNCC) ${ }^{5}$ - documento mais recente, dentre outros documentos discutidos desde a Constituição de 1988. Esses documentos expõem o que precisa ser considerado como função sociopolítica e pedagógica das instituições de educação infantil, apresentando eixos que refletem grande parte das discussões na área e preconizam orientações sobre o que se deseja no trabalho com as crianças. A Teoria Sócio-histórica se faz presente dentro destes documentos, pois muitos desses eixos consideram as relações da criança com o outro para o desenvolvimento de sua aprendizagem (MALETTA, et al, 2008). Os eixos estruturantes da Educação Infantil devem ocorrer através das interações e brincadeiras, focando em "experiências nas quais as crianças podem construir e apropriar-se de conhecimentos por meio de suas ações e interações com seus pares e com os adultos, o que possibilita aprendizagens, desenvolvimento e socialização” (BNCC, 2018, p.25).

A BNCC estabelece cinco campos de experiências: 1- O eu, o outros e o nós; 2- Corpo, gestos e movimentos; 3- Traços, sons, cores e formas; 4-Oralidade e escrita; 5- Espaços, tempos,

\footnotetext{
${ }^{5}$ A Base Nacional Comum Curricular apresenta os Direitos e Objetivos de Aprendizagem e Desenvolvimento como orientação para a elaboração dos currículos para as diferentes etapas de escolarização, dentre elas a Educação Infantil (BNCC, 2018).
} 
quantidades, relações e transformações. Desta forma o desenvolvimento destes eixos trabalhados de forma lúdica, e mediados pela relação com o outro tem grandes possibilidades de auxiliar o desenvolvimento da linguagem nas crianças, pois o brincar possibilita que a criança crie, se comunique imagine e expresse suas manifestações e desejos.

\section{RELAÇÃO CONTEXTUAL NO DESENVOLVIMENTO DA LINGUAGEM NOS PRIMEIROS ANOS DE DESENVOLVIMENTO DA CRIANÇA}

Vygotsky (1993, apud SCHERMACK, 2011) destaca que a função principal da linguagem é a comunicação, o intercâmbio social: é para se comunicar com os outros que o homem cria e utiliza seus sistemas de linguagem. E, ainda de acordo com ele é a necessidade gerada pela comunicação que vai impulsionar o desenvolvimento da linguagem infantil. Ainda bebê, fica visível essa busca pela comunicação, no início da sua aprendizagem de fala (OLIVEIRA, 1997, apud SCHERMACK, 2011). O que torna esse processo viável é o campo teórico sociointeracionista. "É a dinâmica da sociedade e da cultura que interferem ativamente no curso do desenvolvimento do sujeito, transformando tanto sua relação com a realidade como sua consciência sobre ela" (KRAMER et. al., apud FERRARI, 2014, p. 27). E, para que isso ocorra há uma mudança nas estruturas do pensamento dos sujeitos, que vão se alterando ao longo de seu percurso, a partir dos elementos da cultura que ocasionam meios que se integram às subjetividades de cada ser (VYGOTSKY, 1993).

Quando ocorre o desenvolvimento dos conceitos infantis, mediado pelo intercâmbio verbal com os adultos, acontece uma transição entre o pensamento por complexos e o pensamento por conceitos, despercebidos pela criança, que passa a operar com conceitos e praticar "o pensamento conceitual, mesmo sem perceber ou mesmo ter consciência que está operando estas situações" (VYGOTSKY, 1993, p. 71).

É na relação com o outro que o indivíduo se constrói, ou seja, é um ser social, e é essa experiência de vivência diária, mediada pela linguagem, que faz com que os seres apropriem das formas superiores de pensamento e comportamentos, nesta relação com o mundo exterior, tornando-se humanos a partir deste contato social (VYGOTSKY, 1993; 2001). Através da interação de diálogo com o outro indivíduo, a criança é capaz de desenvolver seu processo de desenvolvimento da língua. Mas, sobretudo, é necessário considerar a particularidade das subjetividades individuais que, segundo Oliveira (1992, apud FERRARI (2014, p. 27)

é a forma como os conteúdos culturais são combinados e processados no interior de cada um de nós. Da mesma forma, o desenvolvimento mental ocorre de maneira única em cada pessoa, a partir de como o mundo é experienciado, e "a 
cultura se torna parte da natureza humana, num processo histórico, que ao longo do desenvolvimento da espécie e do indivíduo, molda o funcionamento psicológico do homem.

Desta maneira, há de considerar o desenvolvimento cultural que possui uma influência típica, não podendo ser comparado a nenhum outro tipo de desenvolvimento, "já que se produz simultaneamente e conjuntamente com o processo de maturação orgânica e posto que seu portador é o organismo infantil em transformação em vias de crescimento e maturação" (VYGOTSKY, 1995, apud RICCI E MESQUITA, 2014, p. 214). E, sobretudo, é no desenvolvimento linguagem na criança, que se pode se ver tão bem esse encontro do desenvolvimento natural e o cultural

$\mathrm{Na}$ literatura, os autores denominam esse processo como o "inpul" linguístico, considerando as experiências linguísticas que a criança recebe do seu meio. Esses estudos também demonstraram que a participação do adulto como interlocutor linguístico é capaz de exercer a ação de demonstrar as intenções comunicativas da criança, na qual buscam aproximar o nível linguístico deste ao seu (BORGES E SALOMÃO, 2003). Os primeiros olhares, expressões faciais e gestos já são considerados intenções comunicativas do bebê. Depois, surgem as vocalizações expressas por eles, com isso, o adulto estabelece o canal de comunicação com a criança a partir dessas manifestações. Um destaque nestas pesquisas foi feito na relação estabelecida entre mãe e filho, pelo contato materno inicial intrauterino, que representa a primeira fonte de atenção e aprendizagem. Essa fala entre mãe-criança e, posteriormente, cuidador-criança, denominada de "morthese", busca estabelecer a comunicação, onde o adulto busca relacionar sua complexidade de fala ao nível linguístico da criança, pois se preocupa mais com o nível de compreensão linguística dela do que com o nível de produção (BORGES e SALOMÃO, 2003). Através dessa fala, a criança organiza e utiliza a informação linguística de acordo com sua disposição, idade e desenvolvimento linguístico, tendo a capacidade de fazer diferentes usos da comunicação, em diferentes momentos de seu desenvolvimento. Uma das primeiras etapas é a criança aprender o vocabulário básico, sendo natural que a qualidade e quantidade da fala dispostas à criança tem um efeito positivo no aparelhamento semântico e sintático. Assim, é de grande relevância considerar esse primeiro processo de socialização interna, estabelecida pela relação familiar no desenvolvimento da fala da criança.

Segundo Borges e Salomão (2003), essa primeira socialização que acontece com os pais, na maior parte das vezes, ocorre de maneira implícita através de interações verbais, e sutilmente têm marcações de papéis e de status. É através dessa linguagem que a criança tem a oportunidade de acessar valores, crenças e regras que estão presentes nestes contextos, e assim formando-se culturalmente. 
Uma nova configuração se estabelece quando outros sujeitos sociais começam a fazer parte da vida da criança, essa relação estabelecida com os adultos, ocasiona um desenvolvimento das habilidades linguísticas, numa relação recíproca e bidirecional. Vygotsky nos ajuda a compreender este avanço através dos conceitos de Zona de Desenvolvimento Proximal (ZDP) e Zona de Desenvolvimento Real (ZDR) ${ }^{6}$. No desenvolvimento linguístico, os sujeitos sociais mais próximos - pais, colegas, professores etc - que detêm um nível mais elevado de conhecimento, desempenham esse papel, fazendo com que a criança desenvolva ainda mais seu nível linguístico potencial por que, principalmente, estimulam a vocalização.

A linguagem tem um papel fundamental na aprendizagem infantil, visto que é por meio dela que a comunicação ocorre, e também como sua segunda função de tornar o pensamento generalizante. Desta forma, a linguagem além de possibilitar a comunicação entre os sujeitos, ela simplifica e generaliza a experiência criando categorias conceituais, capazes de facilitar o processo de abstração e generalização, ou seja, o pensamento generalizante que ordena o real agrupa-os em conjuntos, que possuam as mesmas características gerais.

Os estudos de Vygotsky demonstram que, por volta dos 24 meses, ocorre um momento crucial no percurso do desenvolvimento infantil: a aquisição do pensamento conceitual encontrase com o da linguagem, e inicia-se uma forma de funcionamento psicológico, onde a fala torna-se intelectual, com a função simbólica, generalizante e o pensamento torna-se verbal mediado por significados dados pela linguagem. Segundo o autor, "o desenvolvimento do pensamento é determinado pela linguagem, ou seja, pelos instrumentos linguísticos do pensamento e pela experiência sociocultural da criança" (VYGOTSKY, 1993, p. 54). O pensamento não se reflete na palavra, mas nela se realiza, pois é a linguagem que permite a transmissão do pensamento. Para o autor, a linguagem e o pensamento se interligam no processo do desenvolvimento da criança, e o significado passa a ocupar um lugar central, pois o significado da palavra e o pensamento unem-se em um pensamento verbal.

Como o ser humano só é capaz de construir sua história em conjunto com outros sujeitos, é dentro dessa relação interacionista e sócio-histórica que surgem elementos impulsionadores dessa construção do indivíduo. Por isso, faz-se necessário compreender alguns conceitos dessa teoria,

\footnotetext{
${ }^{6}$ A relação entre estes conceitos pode ser estudada em: Constructivista el constructivismo y la innovacion pedagógica (FLORÊNCIO, Roberto Remígio e SANTOS, Carlos Alberto Batista, in: Actas del VI Congreso Internacional Latina de Communicación Social. Universidad de La Laguna - Tenerife, Espanha: 2014. Resumindo, podemos identificar a ZDP (Zona de Desenvolvimento Proximal) como a capacidade de aprendizagem, enquanto a ZDR (Zona de Desenvolvimento Real) é a distância entre o nível de desenvolvimento real, ou seja, determinado pela capacidade de resolver problemas independentemente, e o nível de desenvolvimento proximal, demarcado pela capacidade de solucionar problemas com ajuda de um parceiro mais experiente e a possibilidade real de aprendizagem.
} 
que participam desse processo de aquisição da linguagem e de construção de conhecimento, entre eles, os conceitos de mediação, signo-significado e palavra.

No que tange o conceito de mediação, essa consiste num "processo de intervenção de um elemento intermediário numa relação; a relação deixa, então, de ser direta e passa a ser mediada por esse elemento", é ainda esse processo que vai constituir os processos mentais superiores, segundo Oliveira (1997, apud FERRARI, 2014, p. 30). Então, o que podemos inferir é que a relação entre o sujeito e o meio social, é sempre mediada por produtos culturais humanos, como o instrumento e o signo, e pelo outro indivíduo. O instrumento é um elemento mediador entre o indivíduo e o mundo, ou seja, é um instrumento externo conduzido pela própria natureza, onde o sujeito tem a capacidade de criar seus próprios instrumentos, adequar os existentes e, sobretudo, transmitir sua função no seu grupo social (FLORÊNCIO, 2018).

No que se refere ao signo, de acordo com (OLIVEIRA, 2010, apud SILVA 2012, p. 105), "os signos podem ser definidos como elementos que representam outros objetos, eventos ou situações", constitui um signo: a palavra, desenhos, os símbolos. Nas palavras de Vygotsky, são “instrumentos psicológicos diferindo dos instrumentos externos ou ferramentas na medida em que são orientados para ações psicológicas em relação aos outros ou ao próprio indivíduo" (idem, ibidem). Assim, é o signo, que auxilia nossa mente a tornar-se mais sofisticada, possibilitando um comportamento mais controlado. O que acontece no desenvolvimento da criança é um processo denominado de "mediação simbólica", em que os signos ficam entre os sujeitos e os objetos do mundo, "funcionando como representação social dos objetos e mediando a relação do homem com o mundo e com outros homens", segundo Oliveira (2010, apud SIILVA, 2012, p. 116). E assim, é nesta mediação simbólica que vão ocorrer as funções mentais superiores, e, portanto, a concretude da aprendizagem. São os signos que "auxiliam os processos psicológicos, organizando-os; oferecem suporte concreto para a ação do homem no mundo" (OLIVEIRA, 1993, apud FERRARI, 2014, p. 31). Na origem da formação do conceito, o "signo é a palavra, que a princípio desempenha o papel de meio de formação de um conceito, transformando-se mais tarde em símbolo" (VYGOTSKY, 1993, p. 59). Por meio desta fala, o autor explicita a necessidade de entender os processos pelos quais a criança passa para se chegar a determinada formação de conceitos, que são construídos reconstruídos à medida que ela se envolve com o seu meio sociocultural.

Os estudos de Vygotsky consideram que o desenvolvimento da fala na criança ocorre com movimentos internos e externos. Esse processo de interiorização das funções psicológicas superiores, histórica e cultural, quando externadas através da fala, irão influenciar o aumento da capacidade de desenvolvimento da percepção, atenção, memória e avanço nas manifestações da emoção. Este processo ocorre anteriormente, porém com o desenvolvimento cognitivo estes são 
potencializados (VYGOTSKY, 1993). A linguagem forma um "sistema de mediação simbólica, que funciona como um sistema de instrumento de comunicação, planejamento e autorregulação" (LUCI, 2006, p. 09). É na função comunicativa que acontece a apropriação do mundo externo pela criança, através da interação, movida pela necessidade de negociações e reinterpretações de conceitos e significados.

Quando os indivíduos a interiorizam (a linguagem), passam a ter acesso a estas significações que, por sua vez, servirão de base para que possam significar suas experiências, e serão estas significações resultantes que constituirão suas consciências, mediando, desse modo, suas formas de sentir, pensar e agir (LUCI, 2006, p. 09).

A teoria vygotskyana considera que o significado da palavra só passa a ter sentido quando o pensamento se vincula à fala e se torna um acontecimento linguístico. Ou seja, a união do pensamento e da linguagem, propicia o pensamento verbal, ao qual podemos chamar de "fala significante" (LUCI, 2006). O significado exerce o papel de fazer a mediação simbólica entre a criança e o mundo real; está relacionado ao nível de compreensão da palavra socialmente compartilhado. A transformação dos significados relaciona-se ao significado propriamente dito e ao sentido.

No desenvolvimento da fala, esse sentido de significados é individual, pois ele é influenciado a partir das relações entre os contextos do uso da palavra e as vivências afetivas da quais a criança faz parte. A inserção cultural influencia o desenvolvimento da linguagem, pois é a interação com sujeitos mais maduros, que já têm uma tecnologia linguística mais estruturada. Segundo a perspectiva vygotskiana, a formação do pensamento verbal e a formação dos conceitos não ocorrem de forma mecânica, nem instantaneamente, requer um longo processo, em que o conceito vai sendo transformado nas diversas situações em que é utilizado e "transforma quem o utiliza, ao possibilitar o alargamento das experiências vividas pela capacidade de nomear, evocar, generalizar e orientar o pensamento" (VASCONCELLOS, 2001, apud AQUINO, 2015, p.03). Logo, o pensamento verbal não é constituído de uma forma natural de comportamento, e muito menos inato, mas é influenciado pelo processo histórico-cultural que apresenta propriedades e leis específicas (VYGOTSKY, 1993).

\section{CONSIDERAÇÕES FINAIS}

Desde o nascimento, a criança adentra ao seu meio social e, a partir disso, começa a ser mediada pelas relações familiares, em sua grande maioria, e pelos indivíduos que a cercam. Desta forma, é possível identificar que a fala materna, conhecida como motherese, ou manhês - uma maneira particular de fala da mãe com o bebê - apresenta características - entonação, vozes especiais, altura, ritmo - que passam a ser movimentos de aprendizagem para o bebê. Pelas trocas sonoras, os contatos vão propiciar os primeiros sinais de desenvolvimento linguístico. As primeiras 
manifestações de balbucio, choros e 'besouros' já cumprem a função de comunicar-se, conhecida como a fase pré-intelectual. Passado esse primeiro momento e evoluindo num processo dinâmico de relação de interação com o outro, a criança avança por volta dos 2 anos de idade para a próxima fase (pré-linguística), nesse momento há o encontro da linguagem com o pensamento, onde o processo que caminha junto configura por estabelecer a continuidade do desenvolvimento cognitivo, mediado pela interação social.

O grande salto no desenvolvimento da criança ocorre com aquisição da linguagem, pela qualidade das funções superiores que ela proporciona, quando ela começa a servir de instrumento psicológico para a regulação do comportamento, a percepção muda de forma radical, novas memórias são formadas e novos processos de pensamento são criados. Pode-se concluir que o desenvolvimento da fala da criança depende da quantidade e qualidade da interação que está inserida no ambiente, pois as mediações a que a criança encontra submetida terão influência direta no seu desenvolvimento linguístico. A base da teoria sócio-histórica, desenvolvida por Vygotsky (1993; 2001), está baseada na dimensão constituída pelas relações sociais em que o sujeito se insere, estabelecendo que toda construção de desenvolvimento do ser humano é social: os ambientes influenciam o desenvolvimento infantil, sobretudo na aquisição da linguagem, que sofre as influências do meio social/histórico, no qual todos estamos inseridos.

Esse tema desperta diferentes discussões dentro do arcabouço teórico, sobretudo sobre a necessidade de se compreender os desdobramentos da aprendizagem, mediada pela linguagem e pelos sujeitos ou agentes que o fazem, nessa interação ao longo do percurso do desenvolvimento infantil. Também pela inserção da criança na escola (séries iniciais) e em outros espaços de construção, que ampliam nossa função comunicativa.

As políticas públicas educacionais brasileiras devem atentar para a questão dessas influências vividas pelas crianças nas instituições de desenvolvimento infantil, criando orientações e propostas curriculares escolares, como a atual BNCC (Base Nacional Comum Curricular, BRASIL, 2018), objetivando tornar comum diferentes conhecimentos para assegurar a formação básica das crianças. As leis e os documentos são importantes instrumentos para garantia de direitos, regulamentações, independente se o ensino é público ou particular, nas diferentes regiões do país. No entanto, há de se considerar que essas políticas devem se efetuar concomitantes, com previsão de outras igualdades de condição para que elas ocorram de fato, pois, se contextos e realidades influenciam o processo de desenvolvimento da criança, as regiões (e famílias) apresentam contextos bastante diferenciados. E a formação (e valorização) dos profissionais da educação é o caminho primordial para a qualificação de pessoal especialista na área. Conseguir relacionar a teoria de Vygotsky com o desenvolvimento infantil e com os processos educacionais é de grande relevância 
para (re)conhecimento das práticas educativas, principalmente por identificar sua teoria materializada em políticas públicas reais, como ocorre com a BNCC. Mas, no curso da atuação prática dos professores das séries iniciais, apropriar-se das teorias sociointeracionistas com desenvoltura é imprescindível para promover reflexões sobre a influência que o meio tem na participação do processo de aprendizagem e desenvolvimento da linguagem pelas crianças. Saber como ocorre o desenvolvimento e identificar o que a criança já traz ao chegar ao sistema educacional institucionalizado é relevante para potencializar a relação com o ambiente linguístico, transformando os aprendentes em protagonistas do seu meio social.

\section{REFERÊNCIAS}

AQUINO, L. M. L. Contribuições da teoria histórico-cultural para uma educação infantil como lugar das crianças e infâncias. Fractal: Revista de Psicologia, v. 27, n. 1, p. 39-43, jan.-abr. 2015. Disponível em: < http://www.scielo.br/pdf/fractal/v27n1/1984-0292-fractal-27-10039.pdf. Acesso em 10/03/2019.

BRASIL. Ministério da Educação. Secretaria da Educação Básica. BNCC - Base Nacional Comum Curricular. Brasília: MEC, 2018. Disponível em: $\leq$ basenacionalcomum.mec.gov.br/images/BNCC EI EF 110518 versaofinal site.pdf $>$ Acesso em: 22/04/2019.

BORGES, L.C.; SALOMÃO, N. R. Aquisição da linguagem: considerações da perspectiva da interação social. Psicologia: Reflexão e Crítica, v.16, n. 2, p. 327-336, 2003. Disponível em: < http://www.scielo.br/pdf/prc/v16n2/a13v16n2.pdf>. Acesso em 04/02/2019.

FERRARI, F. M. Desenvolvimento cognitivo: as implicações das teorias de Vygotsky e Piaget no processo de ensino aprendizagem. Disponível em: $<$ http://repositorio.roca.utfpr.edu.br/jspui/bitstream/1/4808/1/MD EDUMTE VII 201434. pdf >. Acesso em 04/02/2019.

FLORENCIO, R. R.; SANTOS, C. A. B. O construtivismo construcionista e a Inovação Pedagógica. In: VI Congreso Internacional Latina de Comunicación Social - Universidade de La Laguna - Tenerife, Ilhas Canárias, Espanha: 2014. Actas del VI Congreso Internacional Latina de Comunicación Social, v. 1, p. 1-13.

FLORÊNCIO, R. R. (2018). Blog Etnolinguagens. Disponível em: www.etnolinguagens.webnode.com, acessado em 10/02/ 2019.

FONSECA, C. M. F. P. As contribuições das teorias da aquisição da linguagem. SynThesis Revista Digital FAPAM, Pará de Minas, v.6, n.6, 78-96, dez. 2015. Disponível em:< http://periodicos.fapam.edu.br/index.php/synthesis/article/download/104/101. Acesso em 07/03/2019.

GIL, A. C. Métodos e Técnicas de Pesquisa Social. 6. ed. São Paulo: Atlas, 2008. 
LUCCI, M. A. A proposta de Vygotsky: a psicologia sóciohistórica. Disponível em: $<$ https://www.ugr.es/ recfpro/rev102COL2port.pdf>. Acesso em 25/02/2019.

MALETTA, A. P. B.; REIS, M. Os Currículos Pensados para a Educação da Infância no Brasil e em Portugal: alguns apontamentos! Rev. Espaço do currículo (online), João Pessoa, v.12, n.1, p. 60-75, jan./abr. 2019. Disponível em:< www.periodicos.ufpb.br/ojs/index.php/rec/.../ufpb.1983-1579.2019v12n1.38745. Acesso em $\underline{23 / 04 / 2019 .}$

RICCI, A. B. P.; MESQUITA, A, F. Ambiente Social e Desenvolvimento da Linguagem de Zero a Dois Anos: Vocabulário e Psicologia. Fevereiro, 2014. Disponível em: $<\underline{\text { https://psicologado.com.br/psicologia-geral/desenvolvimento-humano/ambiente-social-e- }}$ desenvolvimento-da-linguagem-de-zero-a-dois-anos-vocabulario-e-psicologia $>$. Acesso em 06/02/2019.

SCHERMACK, K, Q. O desenvolvimento linguístico infantil na perspectiva interacionista: o papel do outro na aquisição da língua materna. Disponível em: < http://ebooks.pucrs.br/edipucrs/anais/sial/2011/src/20.pdf>. Acesso em 08/02/2019.

SILVA, C. L. Construção sócio-histórica do cérebro na obra de Vigotski. Disponível em:< http://www.teses.usp.br/teses/disponiveis/48/48134/tde-22062012-140612/pt-br.php. Acesso em 20/02/2019.

VIT'TI, S. C.; AZEVEDO, M. A. S. B. Reflexões sobre o desenvolvimento humano na perspectiva histórico-cultural: relações e inter-relações da mediação cultural, da escola e do professor. Disponível http://www.revistas.uniube.br/index.php/rpd/article/viewFile/1219/1411. Acesso em 07/03/2019.

VYGOTSKY, L. S. Pensamento e linguagem. São Paulo: Martins Fontes, 1993.

A Construção do pensamento e da linguagem. São Paulo: Martins Fontes, 2001. 